Information and interaction requirements for software tools supporting analogical design

Gülşen Töre Yargın and Nathan Crilly

Department of Engineering, University of Cambridge

Corresponding author: Gülşen Töre Yargın

Mailing address: Engineering Design Centre,

Department of Engineering,

University of Cambridge,

Trumpington Street,

Cambridge, CB2 1PZ, UK

Phone: 01223748572 email: gt336@cam.ac.uk

Short title: requirements for analogical design tools

Number of pages: 33

Number of figures: 3 


\section{Information and interaction requirements for software tools supporting analogical design}

Abstract: One mode of creative design is for designers to draw analogies that connect the design domain (e.g. a mechanical device) to some other domain from which inspiration is drawn (e.g. a biological system). The identification and application of analogies can be supported by software tools that store, structure, present or propose source domain stimuli from which such analogies might be constructed. For these tools to be effective and not impact the design process in negative ways they must fit well with the information and interaction needs of their users. However, the user requirements for these tools are seldom explicitly discussed. Furthermore, the literature that supports the identification of such requirements is distributed across a number of different domains, including those that address analogical design (especially biomimetics), creativity support tools and human-computer interaction. The requirements that these literatures propose can be divided into those that relate to the information content that the tools provide (e.g. level of abstraction, mode of representation) and those that relate to the interaction qualities that the tools support (e.g. accessibility, share-ability). Examining the relationships between these requirements suggests that tool developers should focus on satisfying the key requirements of open-endedness and accessibility whilst managing the conflicts between the other requirements. Attention to these requirements and the relationships between them promises to yield analogical design support tools that better permit designers to identify and apply source information in their creative work.

Keywords: analogical thinking; design support tools; creativity support tools; design by analogy; user requirements 


\section{INTRODUCTION}

Analogical thinking involves the transfer of information from one domain (the source) to another domain (the target). This analogical transfer is useful when there is some similarity between the source and the target domains (or the relations in those domains) and where that similarity permits reasoning across domains (e.g. Gentner, 1989; Vosniadou \& Ortony, 1989). Where the source domain is familiar and accessible, drawing analogies can make new subjects easier to understand, facilitating the discovery, development, evaluation and exposition of (natural and social) scientific knowledge (Holyoak \& Thagard, 1995, pp. 191, 209). Consequently, analogies are prominently used in many professional practices, including science (Oppenheimer, 1956), medicine (Clarke, 1978), management (Bingham \& Kahl, 2013) and education (Dupin \& Johsua, 1989). Analogical thinking is also central to much design activity where it serves in identifying and solving design problems and in explaining design concepts to others (Christensen \& Schunn, 2007). Collectively, these aspects of analogical thinking provide the opportunity to generate creative design proposals that lead to innovative products, systems and services (Dahl \& Moreau, 2002; Hey et al., 2008; Kalogerakis et al., 2010; Chan et al., 2011).

One of the most difficult challenges in constructing analogies is the retrieval of a plausible source, especially where the search space is large and where the relationship to the target is not obvious (Holland, 1986, pp. 288-9, 312). Such challenges have led to suggestions that it is helpful to have a catalogue of possible sources to draw from and some means of identifying those sources that are related to the targets that are being considered (Linsey et al., 2008). In response to this need, design researchers have developed computer support tools that assist in the construction and application of both cross-domain analogies (e.g. Chakrabarti et al., 2005; Shu, 2010; Vattam \& Goel, 2011; Cheong \& Shu, 2012; Goel et al., 2012; Deldin \& Schuknecht, 2014) and within domain analogies (e.g. Barber et al., 1992; Pearce et al., 
1992; Maher et al., 1995). These tools are often developed to serve two interconnected purposes. First, they represent the types of systems that could be developed to promote and support analogical thinking in design practice. Second, use of these tools provides a basis upon which analogical thinking activities can be studied in observational or experimental research. As such, the tools are both the manifestation of knowledge about analogy-driven design and are also one of the means by which that knowledge is generated. This paper is intended to support these tool development activities and tool use studies by defining and relating the user requirements for such tools. This is founded on two assumptions. First, developing design support tools according to user-centred requirements promises to decrease development time (by providing clearer goals and information about trade-offs) and also to increase uptake (by improving effectiveness and ease of use). Second, analogy-driven design activities are most easily studied when the tools used to support those activities fit well with the requirements of their users.

The need for better software tools is supported by observations of analogy use in professional design practice. Designers have criticised existing tools for not providing effective mechanisms for identifying and applying knowledge from other domains (Kalogerakis et al., 2010, p. 433). The need to adopt a user-centred approach to analogical design tools is recognised in the research community also, with calls to focus on issues of usability, interface design, visualization and search (Goel et al., 2014a). This is part of a more general ambition to develop tools that assist people's creative work without disturbing the natural flow of their activities (Hewett, 2005). In defining the user requirements for analogical design support tools we review three distinct but related areas of literature: the literature on analogical design, creativity support tools and Human-Computer Interaction (HCI). Analogical design tools are our main focus but we view them as a subset of creativity support tools, which are thus relevant to how analogical design tools should be developed. More 
generally, HCI guidelines are also relevant as there are many standards (e.g. ISO 9241 series) and commonly applied heuristics and usability guidelines that should be considered when developing a user interface (e.g. Nielsen, 1994; Schneiderman \& Plaisant, 2005; Galitz, 2007). While developing tools for supporting analogical design, the importance of these generic guidelines is clearly evident. While emphasizing their importance, this paper does not focus on the generic HCI guidelines but instead concentrates on the requirements for supporting analogical design activity within the context of creativity support tools.

To identify user requirements relevant to analogical design support tools, we searched for literature sources that describe the development or use of such tools especially in the context of biomimetics. From the variety of possible analogical sources from which designers might draw, we focus on the biological domain (and biomimetic design tools) for three reasons: (1) because of biomimetics' recent rapid expansion and wide applicability across a range of technologies, problem types and design disciplines (Lepora et al., 2013); (2) because biologically inspired design is by definition based on cross-domain analogies and thus promotes or permits a wide range of analogical distances (Goel et al., 2014b); and (3) because there has been much recent tool development work in this area with associated studies of designer interactions with those tools. We also searched for sources that focus on the design requirements for creativity support software more generally. Within the broader scope of HCI research, we searched for requirements relating to how information should be communicated to system users and what interaction qualities support learning and exploration. This review process resulted in the identification of user requirements that fall into two general groups. The first group contains requirements related to the information content that the tool should provide, such as abstraction (generalisation from specific instances); the second group of requirements contains interaction qualities that the tool should provide so as to support designers' tasks with the tool, such as accessibility (the ease of 
accessing the intended content) Developing tools to satisfy these requirements realises positive outcomes for the analogical design process, either directly or indirectly. To discuss how future tools should be designed, the paper introduces these outcomes and requirements, and examines the relationships between them.

Before proceeding, some clarification of terminology is warranted. We use the term 'tool' to refer to information tools (typically software tools) that assist in constructing analogies that assist with design problems. Designers are the typical users of these tools and we thus use the terms 'designer' and 'user' synonymously, switching between these terms depending on the role that we are emphasising (i.e. the designer as a tool user or the designer as a designer). Where we refer to those who develop these tools, we use the term 'developer' rather than 'designer' to avoid any confusion with the tools' users. (We acknowledge that the tool developers are also designers and that they too could use (analogical) design tools in their work but we do not consider that matter any further here.)

\section{POSITIVE OUTCOMES OF TOOL USE}

The ultimate aim of analogical design support tools is to provide stimuli that assist in the construction of analogies and thus facilitate creative design work. This goal can be achieved by the support tools encouraging two different kinds of positive outcome. There are outcomes that directly relate to the construction and implementation of analogies, and there are outcomes that make uptake of the tool more likely and effective and thus indirectly promote analogical thinking. We first consider the direct outcomes and then the indirect ones.

For creative design, many process models have been suggested in the literature and from those the most commonly identified creativity stages are exploration (or analysis), generation, evaluation and communication (for a recent review see Howard et al., 2008). As illustrated in Figure 1, these stages of creative activity partly map to and partly overlap with the different stages of analogical thinking that have been identified: (1) accessing the 
analogues from some source (e.g. from memory or from a catalogue of some sort); (2) mapping the source analogue with the target analogue by identifying the correspondence between the two; (3) drawing inferences about the target based on these mappings; (4) evaluating those inferences, considering the requirements of the target and adapting them based on these evaluations; and finally (5) learning from the preceding stages to construct new categories and schemas that can be stored as new analogues in long-term memory (Holyoak et al., 2001). Of course, neither creative acts generally, nor analogical thinking in particular are always carried out in this strict sequence but the named stages provide a useful basis for structuring how we consider the impacts that design support tools should have on analogical thinking. Furthermore, apart from supporting analogical design stages, tools are expected to assist with problem reframing activities during the design process (Goel et al., 2012).

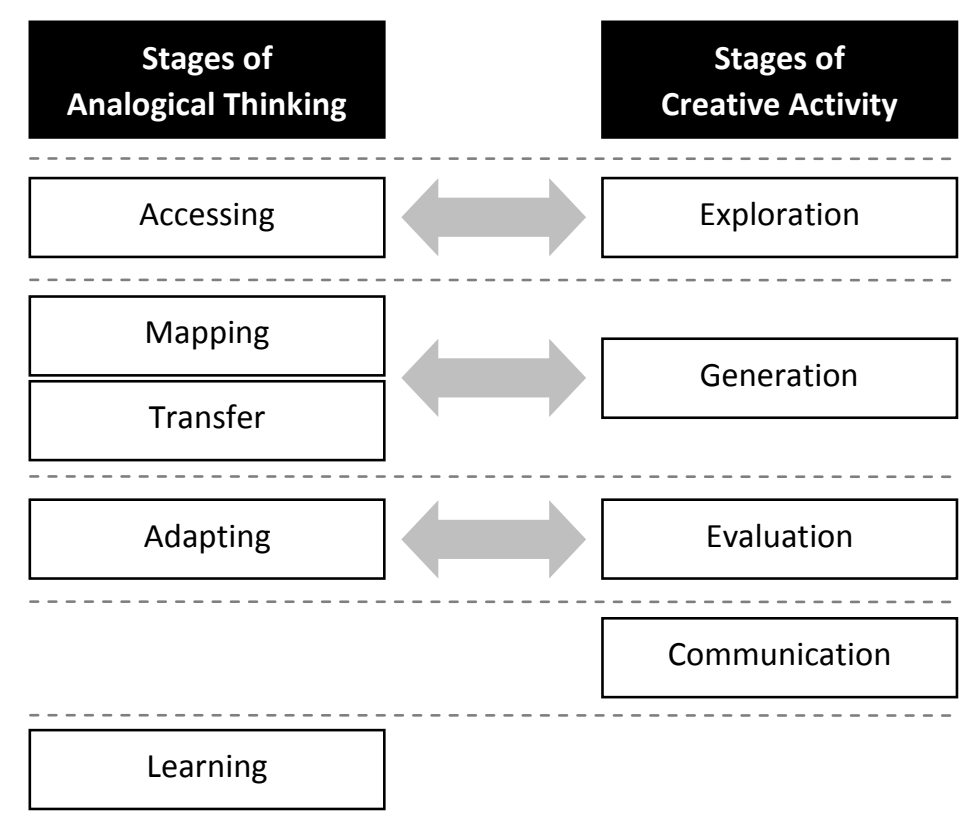

Figure 1. Mapping between the stages of analogical thinking and the stages of creative activity (corresponding stages are indicated with two way arrows). 
Besides seeking to directly impact the analogical design process, support tools can indirectly impact that process by creating desirable conditions under which the tool will be used effectively. First, having an enjoyable, fun or playful software environment motivates users to explore the content and spend more time on using the tool to look for ideas (Elam \& Mead, 1990; Resnick et al., 2005). Maintaining designer efficiency while working with the tool is also essential, requiring an interactive environment free from interruptions to creative flow. If such efficiency is maintained, users can allocate their resources to design tasks rather than focussing on operating the software (Avital \& Te'eni, 2009). Finally, it is important to maintain the users' perceived control over the tasks that are carried out with the tool and to decrease the perceived risk of trying something new (Terry \& Mynatt, 2002; Resnick et al., 2005). When such confidence is combined with intrinsic motivation and a sense of efficiency, the tool can help not just in providing valuable information for creative design, but can also contribute to establishing a psychological state in which such creative acts are more readily performed (Csikszentmihalyi, 1996).

\section{INFORMATION CONTENT PROVIDED BY THE TOOL}

Analogical design support tools primarily provide information about the source (e.g. about a biological system). In providing source information, tool developers must make decisions about what entities to describe, how to group them, what representations to use, how to abstract from examples, how to exemplify these abstractions, and so on. These are all questions about information content and they relate to a critical issue of analogies which is how to reveal the salient features of the source whilst de-emphasising the irrelevant or distracting features (Halasz \& Moran, 1982; Spiro et al., 1989).

\subsection{Abstraction: Deriving General Principles from Specific Instances}

Presenting source information to designers is intended to promote creative thought, but there is the risk that rather than providing inspiring new ways to view a problem, the information 
instead leads to a blind repetition of unhelpful or limiting features of the stimuli (Jansson \& Smith, 1991; Cardoso \& Badke-Schaub, 2011; Goldschmidt, 2011). This fixation effect has been observed in biologically inspired design activities, where the biological stimuli limit the exploration to that one source (Mak \& Shu, 2008; Helms et al., 2009). Attempts to remedy this problem can involve one of two related options: either the stimuli are presented in a more abstract form or the stimuli are related in a way that emphasises general principles rather than detailed features. In either case, some principle of abstraction is used to modify or group the stimuli. This abstraction is often achieved by describing biological entities with function based ontologies (Chakrabarti et al., 2005; Vincent et al., 2006; Nagel et al., 2010; Shu, 2010; Vattam \& Goel, 2011; Cheong \& Shu, 2012; Goel et al., 2012; Deldin \& Schuknecht, 2014).

\subsection{Exemplification: Illustrating General Principles with Specific Instances}

Whilst abstraction is useful for identifying the general principles that apply across domains, concrete exemplifications of these principles are beneficial for the designer to understand the ways in which they are implemented. Especially for novice designers, reasoning from individual cases may be easier than reasoning from abstract principles (Bonnardel, 2000; Ball et al., 2004), and the examples may help in transferring those principles into the design (Hewett \& DePaul, 2000; Töre Yargın, 2013). For instance, in the AskNature database (The Biomimicry 3.8 Institute, 2008-2014) it is possible to browse product examples and design strategies which perform similar functions. This is claimed to enable users to explore different problem solving strategies regarding a particular challenge or to get inspiration while browsing those strategies (Deldin \& Schuknecht, 2014). Moreover, Cheong and Shu (2013) suggest that providing multiple examples can enable the designer to recognize shared principles at a more abstract level because a variety of examples will not share the same superficial similarities. 


\subsection{Mode of Representation: Displaying Text, Drawings, Photographs, etc.}

Whether describing concrete examples or abstract principles, tool developers can present information in various ways by using text, drawings, photographs, animations, diagrams, equations, graphs and other modes of representation (e.g. Chakrabarti et al., 2005; Goel et al., 2012). Some modes of representation are more effective than others for certain creative tasks, affecting the quantity, quality, and diversity of ideas generated (Fischer, 1993; Yamamoto \& Nakakoji, 2005; Sarkar \& Chakrabarti, 2008; Cardoso \& Badke-Schaub, 2011). Combining different modalities such as augmenting textual descriptions of an organism with diagrams of function structures can improve the ability of designers to produce novel solutions (Linsey et al., 2008). Therefore, beyond just selecting the most appropriate mode of representation, providing the content in various forms enables the user to explore the content from multiple perspectives, thus maintaining a holistic perspective that promotes creativity (Candy \& Edmonds, 1995; Candy \& Edmonds, 1997; Hewett \& DePaul, 2000; Avital \& Te'eni, 2009).

\subsection{Open-endedness: Permitting Different Interpretations of the Information}

Related to issues of abstraction, exemplification and representation is the issue of how openended the content is. This involves encouraging users to perceive the content as being ambiguous, incomplete, uncertain, tentative, provisional or partial, leading to further exploration and meaning-making activities (Candy \& Edmonds, 1996; Gaver et al., 2003). If, instead, content is perceived as closed, definite and finished, it is hard for users to conduct further exploration as the material is seen as an answer rather than a point of departure, which can result in fixation (Diggins \& Tolmie, 2003; Töre Yargın, 2013). The degree of openendedness that is provided in the stimuli should be specified by considering the type of analogical design process: "while precise comprehension of biological systems can be ideal for detailed designs, for the purpose of concept generation, ambiguity and 'generalness' can also be useful" (Mak \& Shu, 2008, p.28). Leaving content open to interpretation can be 
achieved through the judicious use of abstraction and exemplification and through selecting modes of representation that do not overdetermine the interpretations that are possible.

\subsection{Concision: Balancing Brevity with Completeness}

In providing information on the source domain, tool developers must decide how concise that information should be and how brevity should be balanced against completeness (Töre Yargin, 2013). It is well-known that many designers, especially in the early stages of design, have a tendency to overlook exhaustive reports in favour of more succinct guidance (Ramey et al., 1992; Kuniavsky, 2003; Bartocci et al., 2008). For the sake of system clarity, giving excessive information should be avoided since this may distract from the core underlying principles being communicated or may discourage sufficient browsing of multiple items (Diggins \& Tolmie, 2003; Nørgaard \& Hornbæk, 2009). On the other hand, the information should provide sufficient context so that the principle or example can be understood (Diggins \& Tolmie, 2003; Blomberg \& Burrell, 2008). Providing multiple levels of detail is one strategy to overcome the competing objectives of providing information that is concise yet complete. However, multiplicity of information is a requirement that applies to more than the degree of concision and so is considered separately in the next section.

\subsection{Multiplicity: Maintaining Diversity and Variety of Content}

From the five preceding sub-sections (sections $3.1-3.5$ ), it is clear that information from the source domain can be provided in many different ways. It is not necessarily the case that tool developers must make definitive decisions on each of these as they can choose to provide information in multiple ways concurrently. For instance, information can be provided at multiple levels of abstraction, from detailed examples to overall general principles so that the user can identify analogical similarity at these different levels (Avital \& Te'eni, 2009; Goel et al., 2012). Developers can provide multiple examples of entities that exhibit a similar property so that users can understand the abstracted principles better or so that they can perform that 
abstraction themselves (Hewett \& DePaul, 2000; Deldin \& Schuknecht, 2014). Different levels of abstraction can also be provided to allow users to identify patterns, commonalities and anomalies that are not obviously seen at any one level (Avital \& Te'eni, 2009) and to thus more readily encourage the construction of useful analogies for design (Chakrabarti et al., 2005; Goel et al., 2012). Similarly, multiple modes of representation and multiple degrees of open-endedness and concision are possible.

\section{INTERACTION QUALITIES PROVIDED BY THE TOOL}

Beyond providing the right information in the right forms, it is important that tool developers consider the qualities of the interactions that users will have with that information. Developers must decide on how information can be accessed (e.g. searched or browsed), to what extent it can be modified or rearranged and in what ways it can be shared. They must also consider how transparent the tool is and how well it connects with other systems or processes that the designer is using. These kinds of requirements for interaction are discussed here before their relationships with each other, with the information content requirements and with the intended outcomes are discussed in Section 5.

\subsection{Accessibility: Allowing Easy Retrieval of the Content}

Tool users might have a clear idea what they are looking for and wish to search the database for keywords that they know to be relevant to their problem or solution. To prevent the list of search results becoming unmanageable, developers can implement model-based tagging that assists with 'information foraging' (Vattam \& Goel, 2011), categorised search lists (Shu, 2010; Cheong \& Shu, 2012) or interactive overviews of categorized search results (Kules, 2005; Kules \& Shneiderman, 2008). Such categorisation of the data also permits browsing rather than searching, where users might accidentally find information that they could not have known to search for (Vattam \& Goel, 2013). Different principles of classification are possible, but function-based classifications are most commonly adopted in bio-inspired design 
tools (see Section 3.1). These ontologies traditionally emphasise the function, behaviour and structure (or state) of the entities that are being classified or related. Other classification schemes are possible however, and recent work has suggested that classification might also be conducted according to concepts of operating environment, performance criteria, deficiencies, benefits, constraints or specifications (Helms \& Goel, 2013).

\subsection{Interactivity: Providing Active Control and Continuous Feedback}

Although the importance of interactivity is not commonly referred to in the analogical design support literature, its importance is evident in the literature on supporting creativity. Searching and browsing are ways in which users interact with the information content but other forms of interaction are also possible. Interactivity is a complex quality, the definition of which is not commonly agreed on (Liu \& Shrum, 2002; Johnson et al., 2006). However, there are some recurring constructs in operational definitions of interactivity, including 'active control' and 'reciprocity in communication'. These can be considered as common dimensions, which support exploration by enabling the tool to "talk back to the users" (Resnick et al., 2005). To achieve this, it is important to provide continuous feedback and to maintain a sense of directness in interaction. Direct manipulation interfaces can facilitate interactive search queries by providing instant categorizations and visualizations to interpret the findings of research outcomes (Shneiderman, 1997) and such interactions can also support exploration of the content of analogical design tools.

\subsection{Transparency: Providing Clarity in Interaction}

Whilst interacting with a tool, users may form an image of the way in which it works and the way in which they should use it. One way to assist in this is to transparently represent the tool's internal processes so that users can feel that they are directly interacting with the process itself promoting uptake of the tool (Edmonds et al., 2005). However, the tool should learn the user's language and practices, not the other way around (Fischer, 1993), allowing 
users to spend their resources on more valuable design activities (Resnick et al., 2005; Avital \& Te'eni, 2009). Therefore, developers should identify suitable "black boxes" or "building blocks" which enable the user to interact with the system to carry out design-related tasks, whilst disguising any underlying mechanisms that are irrelevant to those tasks (Resnick et al., 2005). Web-based environments and typical web-based interaction styles are one approach to providing an interface which most computer-literate people can use, thus promoting exploration and uptake (Deldin \& Schuknecht, 2014). Web-based environments also raise the possibility of easily connecting analogical design support tools with other systems and processes that designers engage in.

\subsection{Connectivity: Integrating the Tool with Other Systems}

During the design process, designers might use different systems to locate information, document their thoughts and record the progress made (e.g. CAD software, digital sketching and prototyping tools). Interoperability between these environments has proved important for supporting design activities (Shneiderman, 2000; Resnick et al., 2005; Avital \& Te'eni, 2009). Similarly, having an integrated way of working with analogical design support tools would be beneficial, especially as the use of analogical design support tools might prompt further information searches outside the tool itself. For example, in response to locating an item of information in the tool, users may search the internet, digital libraries and other databases. Integrating with these other systems might involve allowing modifications to the tool itself and the addition of user-generated content found elsewhere (Hewett \& DePaul, 2000; Avital $\&$ Te'eni, 2009). To achieve this, collaboration features which allow peer-production of content are proposed for both the AskNature (Deldin \& Schuknecht, 2014) and DANE tools (Goel et al., 2012). 


\subsection{Share-ability: Allowing Content to Be Communicated to Other Stakeholders}

Design processes often involve collaboration, even more so when the proposed designs draw on information or solutions from outside the designers' expertise (e.g. when drawing from the biological domain). Consequently, it is important that the content of the tool and the outcome of the user's progress should be shareable with other experts and stakeholders (Hewett \& DePaul, 2000; Edmonds et al., 2005; Avital \& Te'eni, 2009). This 'share-ability' of information supports effective communication within the design team and between the design team and others, thus promoting collaboration (Erickson, 1998; Hughes et al., 2000). However, the level of detail that designers require for communication may differ from the level of detail at which they are working (Edmonds et al., 2005). For example a software programmer may want to work with symbolic codes but find it more productive to share information and ideas with others using visual representations. Therefore analogical design support tools might provide representations of information in different modes not just to enable analogy building, but also to enable analogy sharing.

\subsection{Restoration: Permitting the Resumption of Previous Activities}

The importance of storing and returning to earlier states and activities is commonly emphasized for supporting work efficiency during creative activities (Elam \& Mead, 1990; Hewett \& DePaul, 2000; Shneiderman, 2000). The ability to store the history of a work session and then return to different points in that history can support designers in attending to other tasks and deferring judgements, both of which can support divergent thinking (Elam \& Mead, 1990). The restoration of prior states can be assisted by tool functionality that permits the naming, storing and sorting of search sessions. An alternative approach is to provide features for browsing sessions to be recorded, retrieved and reviewed. Whether by search or browse, it can be useful to allow designers to document their thoughts and decisions so that they and other stakeholders can retrieve the rationale for the design decisions that they make 
(Bracewell et al., 2009). In order to not unnecessarily disrupt thought processes during these activities, the interface should permit flexibility in generating, storing and retrieving ideas (Hewett \& DePaul, 2000).

\subsection{Adaptability: Allowing the Nature of the Interactions to Change}

Analogical design tools should be adaptable and customisable for different users (e.g. expert vs. novice) and different working styles (e.g. systematic approaches vs. or inspiration-driven styles) (Resnick et al., 2005). In addition, there can also be different tasks to which the tool is applied, each of which might be better suited to different modes of interaction with the tool (Töre Yargın \& Erbuğ, 2012). This adaptability can be implemented manually, with the user able to detect which features correspond to a given working style (Hewett \& DePaul, 2000; Avital \& Te'eni, 2009). Alternatively, the tool can learn the user's pattern of working, adapting the tool to fit and automating certain tasks to improve work efficiency (Avital \& Te'eni, 2009). Moreover, the tool should be adaptable to different problem definition and reframing needs. For example, Chakrabarti et al. (2005) suggest two different ways of exploring the content of their IdeaINSPIRE tool based on how well the design problem can be defined by the user. Likewise, Helms et al. (2009) define problem-based and solution-based processes for biologically inspired design and suggest features in the DANE tool to support these processes (Goel et al., 2012).

\section{THE RELATIONSHIPS BETWEEN REQUIREMENTS AND OUTCOMES}

Developing tools that satisfy the user requirements for information content and interaction quality promises to deliver direct and indirect positive outcomes for the analogical design

process. The requirements have complex relationships with each other and with the desired outcomes, as illustrated in Figure 2. 


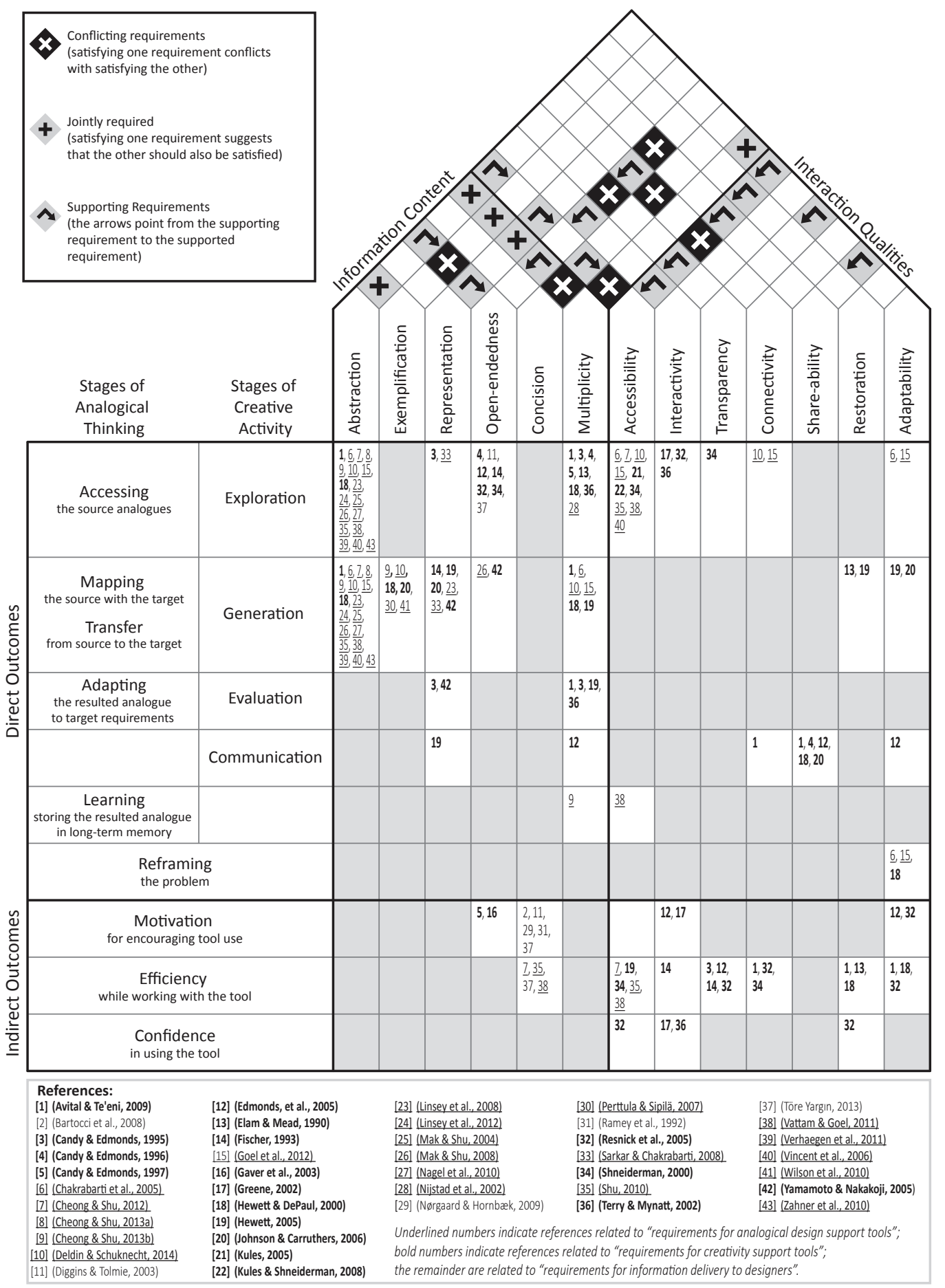

Figure 2. Matrices illustrating the relationships between outcomes (rows) and requirements (columns). The numbers in the cells of the rectangular matrix indicate the relevant literature discussing the relation between a specific outcome and specific requirement. The symbols in the cells of the triangular matrix indicate the relationships between requirements. 
In the triangular matrix in Figure 2, we see that the relationships between requirements can be (1) conflicting, indicating that trade-offs must be made, (2) jointly required, indicating that they should be maintained together, and (3) supporting, indicating that satisfaction of one positively impacts the other. Close inspection of Figure 2 reveals that two of the requirements (open-endedness and accessibility) are more heavily supported than the others. This can be interpreted as those other requirements serving as the means by which open-endedness and accessibility are achieved, which are in turn, the means by which the positive outcomes are achieved. Having identified open-endedness and accessibility as key requirements, we can sort the rest of the requirements into three groups based on their relationships with openendedness and accessibility: (1) requirements supporting both open-endedness and accessibility, (2) conflict generating requirements (those that generate conflicts between openendedness and accessibility) and (3) conflict resolving requirements (those that resolve the conflicts generated between open-endedness and accessibility). In Figure 3, these groups of requirements are illustrated in a network diagram to better represent the relationships between the requirements and how these might be considered during tool development. Each of these relationships is discussed in turn below.

\section{Requirements supporting both open-endedness and accessibility: Representation,} interactivity and abstraction are the three requirements which each support both of the key requirements. Certain modes of representation are more abstract, ambiguous or multi-layered than others and such modes are thus more open to interpretation, permitting designers to explore (and re-explore) the content from different perspectives. Selecting the right mode of representation can also make the content more accessible by quickly revealing the most salient features whilst still permitting deeper exploration (The Biomimicry 3.8 Institute, 20082014). Enhancing a tool's interactivity means increasing the degree to which it provides continuous, reciprocal and immediate feedback. By allowing users to work with, rather than 
just read from, the required content, different ways of viewing the content can be explored, making it more accessible. Current tools can benefit from direct manipulation mediums and interactive search facilities which can provide instant categorisations and visualisations (Shneiderman, 1997). Through abstraction of the content, classification is implied, which makes the content more accessible though search and browse activities (Chakrabarti et al., 2005; Vincent et al., 2006; Shu, 2010; Vattam \& Goel, 2011; Cheong \& Shu, 2012; Goel et al., 2012; Deldin \& Schuknecht, 2014). Abstracted principles are also more open-ended as they eliminate details to represent more general principles (Mak \& Shu, 2008).

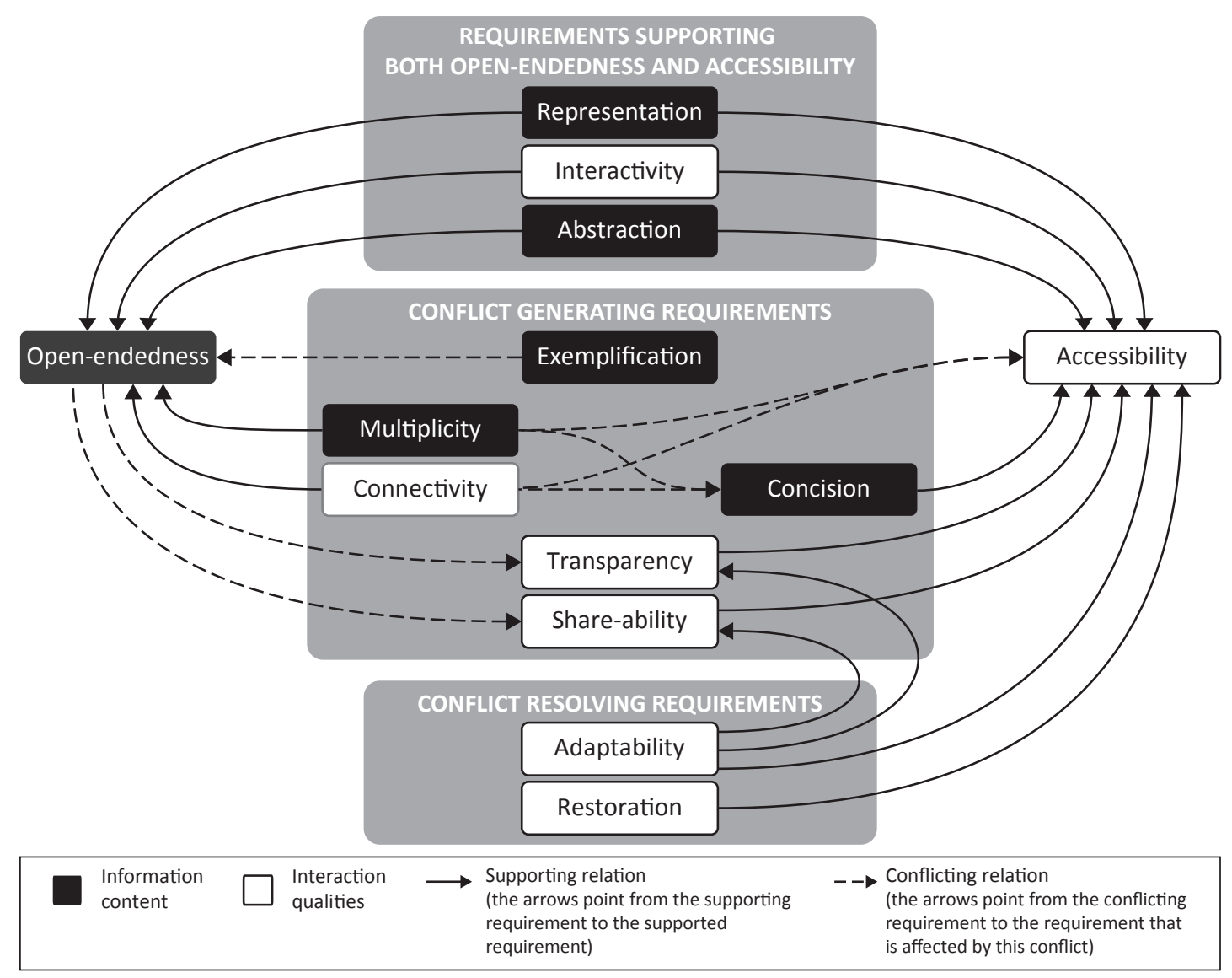

Figure 3. Network diagram of the supporting and conflicting relationships between individual requirements. 
Conflict generating requirements: Exemplification, multiplicity, connectivity, concision, transparency, and share-ability all conflict with one of the two key requirements and yet are also important to the delivering the required positive outcomes. This requires tool developers to make trade-offs in balancing the requirements they satisfy. Exemplification is important to clarify abstracted principles, but in so doing, makes those principles less general and risks inducing fixation, thus conflicting with open-endedness. To avoid this, surfacedissimilar, unusual and multiple varied examples should be provided (Nijstad et al., 2002; Perttula \& Sipilä, 2007; Wilson et al., 2010). In that sense, multiplicity supports openendedness of the content and can help designers to avoid or overcome fixation. Connectivity also supports open-ended interpretation of the content by allowing the designer to access different sources or systems and to connect the information in new ways. Search tools based on a natural-language approach that can be connected to different sources can potentially allow designers to access a diversity of sources, thus facilitating more open ended discovery (Shu, 2010). Despite their benefits, multiplicity and connectivity both conflict with concision and accessibility, because they broaden and complicate the possible sources and formats of material available. Categorising the search outcomes and filtering the irrelevant and frequently appearing words are some of the strategies that are adopted to deal with this conflict (Cheong \& Shu, 2012). Transparency enables the user to understand how to interact with the tool and thus supports accessibility, but open-endedness can conflict with this requirement, since making the content open to interpretation can reduce clarity. In addition, making the content share-able between the stakeholders in the team increases its accessibility for team members, whereas making it open-ended and interpretable can reduce its shareability. This is because everybody who uses the tool has their own interpretations and it can thus be hard to have shared understanding within the team's communication (Stacey \& Eckert, 2003). 
Conflict resolving requirements: Adaptability and restoration are requirements which can resolve the conflicts discussed above. Maintaining diversity in the content and connecting the tool with other systems can jeopardise its accessibility. One way to resolve this is to make the tool adaptable by providing ways to filter the information or change the mode of interaction based on user needs and preferences (e.g. whether for problem-oriented or solution-oriented design processes in Goel et al., 2012). Likewise, through adaptability the system can be made more transparent as the irrelevant content can be flexibly filtered out, preventing it from obscuring the information and interactions that are necessary. Also, adaptability can make the content more sharable since that content can then be modified for the needs and preferences of different of users. Another way to overcome the challenges to accessibility is to implement restoration, thus making prior states more accessible, potentially for different users (Hewett \& DePaul, 2000).

As in other areas of design, identifying and reconciling conflicting requirements in tool development is important for innovation, and developers should attend to the conflicts highlighted above. However, other relationships between the requirements might also be relevant and this should be investigated in future work.

\section{DISCUSSION}

In reviewing user requirements for tools that support analogical design, a number of avenues for future work emerge. This work would provide further guidance on how such tools should be developed by better understanding those requirements that are conflicting, poorly defined or poorly supported. For example, considering the requirements for information content, the issue of abstraction raises a number of research issues. Abstraction is one of the key principles for analogical transfer, but it is important to identify the right principles upon which to perform the abstraction. To date, function has been the most common principle of abstraction and classification. However, function is a problematic concept (e.g. Crilly, 2010; Vermaas \& 
Eckert, 2013), and other complementary principles of abstraction might be used, including, those relating to system architectures such as modularity, redundancy, robustness and scalability (e.g. Hastings \& McManus, 2004; Knippers \& Speck, 2012; Chen \& Crilly, 2014). Future work could usefully identify the variety of abstraction principles that might be applied and seek to understand how they might most effectively be selected from or combined.

Considering the requirements for interaction qualities, the related issue of accessibility is also important. This is because the searching and browsing activities by which content is accessed influences - or is even determined by - the principles upon which that content is abstracted. Furthermore, in order to develop tools that integrate with the other systems that designers use, providing connectivity is important. Better understanding the requirement for connectivity requires research into the variety of existing tools, systems and processes that are relevant to analogical design and research into the real world contexts in which those tools are used and in which analogical design takes place. In order to investigate their expectations, past experiences of designers who have expertise in analogical design should be consulted to understand their information and interaction needs, while accessing source analogues and mapping and transferring from source analogues to the target solution. Identifying these criteria is necessary both for developing future tools and also for evaluating them. This would yield guidance on the standards, conventions and terminology that should be adopted within and across tools.

Analogical design support tools can serve designers in some of the most difficult challenges in design: the identification of principles and precedents that are related to (however distantly) the design task under consideration. For developers striving to provide such tools there are a number of activities that must be undertaken. They must generate a broad and detailed catalogue of possible sources for designers to draw from; they must determine how that information should be structured and presented; they must also implement 
an interface to that information that promotes interactions that are engaging and effective. These activities should satisfy the requirements of the tools' users, that is, the designers who will work with them. Developing design support tools according to those requirements promises to decrease development time and also to increase uptake. We have sought to gather such requirements in this paper and have explored the relationships between them.

Conducting further work into these requirements and their relations would provide a more solid foundation upon which analogical design support tools can be developed and deployed, and assist in realising their potential in design research, practice and education.

\section{Acknowledgments}

Dr Gülşen Töre Yargın’s work was supported by the International Post Doctoral Research Fellowship Programme [BIDEB-2219] from the Scientific and Technological Research Council of Turkey (TÜBİTAK). Dr Nathan Crilly's work was supported by an Early Career Fellowship [EP/K008196/1] from the UK's Engineering and Physical Sciences Research Council (EPSRC).

\section{References}

Avital, M., \& Te'eni, D. (2009). From generative fit to generative capacity: exploring an emerging dimension of information systems design and task performance. Information Systems Journal, 19(4), 345-367.

Ball, L.J., Ormerod, T.C., \& Morley, N.J. (2004). Spontaneous analogising in engineering design: a comparative analysis of experts and novices. Design Studies, 25(5), 495-508. Barber, J., Bhatta, S., Goel, A., Jacobson, M., Pearce, M., Penberthy, L., Shankar, M., Simpson, R., \& Stroulia, E. (1992). AskJef: integration of case-based and multimedia technologies for interface design support. In Artificial Intelligence in Design'92, (Gero, J.S., Ed.), pp. 457-475. Dordrecht: Kluwer. 
Bartocci, G., Potts, L., \& Cotugno, C. (2008). Experience report: communicating ethnographic findings effectively within multidisciplinary teams and to your clients. Proc. Int. Conf. on Design of Communication, SIGDOC '08, pp. 99-102. Portugal: ACM.

Bingham, C.B., \& Kahl, S.J. (2013). The Process of Schema Emergence: Assimilation, Deconstruction, Unitization and the Plurality of Analogies. Academy of Management Journal, $56(1), 14-34$.

Blomberg, J., \& Burrell, M. (2008). An ethnographic approach to design. In The HumanComputer Interaction Handbook, (Sears, A., \& Jacko, J.A., Eds.), pp. 965-988. New York: Taylor \& Francis.

Bonnardel, N. (2000). Towards understanding and supporting creativity in design: analogies in a constrained cognitive environment. Knowledge-Based Systems, 13(7-8), 505-513.

Bracewell, R., Wallace, K., Moss, M., \& Knott, D. (2009). Capturing design rationale. Computer-Aided Design, 41(3), 173-186.

Candy, L., \& Edmonds, E. (1995). Creativity in knowledge work: A process model and requirements for support. Proc. OZCHI'95, HCI: A Light into the Future, Vol. 95, pp. 242248. Wollongong, NSW: CHISIG.

Candy, L., \& Edmonds, E. (1996). Creative design of the Lotus bicycle: implications for knowledge support systems research. Design Studies, 17(1), 71-90.

Candy, L., \& Edmonds, E. (1997). Supporting the creative user: a criteria-based approach to interaction design. Design Studies, 18(2), 185-194.

Cardoso, C., \& Badke-Schaub, P. (2011). Fixation or Inspiration: Creative Problem Solving in Design. The Journal of Creative Behavior, 45(2), 77-82.

Chakrabarti, A., Sarkar, P., Leelavathamma, B., \& Nataraju, B. (2005). A functional representation for aiding biomimetic and artificial inspiration of new ideas. Artificial Intelligence for Engineering Design, Analysis and Manufacturing, 19(2), 113-132. 
Chan, J., Fu, K., Schunn, C., Cagan, J., Wood, K., \& Kotovsky, K. (2011). On the benefits and pitfalls of analogies for innovative design: Ideation performance based on analogical distance, commonness, and modality of examples. Journal of Mechanical Design, 133(8), 081004.

Chen, C.-C., \& Crilly, N. (2014). Modularity, redundancy and degeneracy: Cross-domain perspectives on key design principles. Proc. 8th Annual IEEE Systems Conf., SysCon 2014, pp. 546-553. Ottawa, Canada: IEEE.

Cheong, H., \& Shu, L. (2012). Automatic extraction of causally related functions from natural-language text for biomimetic design. Proc. ASME 2012 Int. Design Engineering Technical Conf. \& Computers and Information in Engineering Conf., pp. 373-382. Chicago, IL: ASME.

Cheong, H., \& Shu, L. (2013). Using templates and mapping strategies to support analogical transfer in biomimetic design. Design Studies, 34(6), 706-728.

Christensen, B.T., \& Schunn, C.D. (2007). The relationship of analogical distance to analogical function and preinventive structure: The case of engineering design. Memory \& cognition, 35(1), 29-38.

Clarke, E. (1978). The neural circulation. The use of analogy in medicine. Medical History, 22(3), 291-307.

Crilly, N. (2010). The roles that artefacts play: technical, social and aesthetic functions. Design Studies, 31(4), 311-344.

Csikszentmihalyi, M. (1996). Creativity: flow and the psychology of discovery and invention. New York, NY: Harper Perennial.

Dahl, D.W., \& Moreau, P. (2002). The influence and value of analogical thinking during new product ideation. Journal of Marketing Research, 39(1), 47-60. 
Deldin, J.-M., \& Schuknecht, M. (2014). The AskNature Database: Enabling Solutions in Biomimetic Design. In Biologically Inspired Design, (Goel, A.K., et al., Eds.), pp. 17-27. London: Springer-Verlag.

Diggins, T., \& Tolmie, P. (2003). The 'adequate' design of ethnographic outputs for practice: some explorations of the characteristics of design resources. Personal and Ubiquitous Computing, 7(3), 147-158.

Dupin, J.J., \& Johsua, S. (1989). Analogies and “modeling analogies" in teaching: Some examples in basic electricity. Science Education, 73(2), 207-224.

Edmonds, E.A., Weakley, A., Candy, L., Fell, M., Knott, R., \& Pauletto, S. (2005). The studio as laboratory: combining creative practice and digital technology research. International Journal of Human-Computer Studies, 63(4), 452-481.

Elam, J.J., \& Mead, M. (1990). Can software influence creativity? Information Systems Research, 1(1), 1-22.

Erickson, T. (1998). Towards a pattern language for interaction design. In Recovering Work Practice and Informing Systems Design, (Luff, P., et al., Eds.), pp. 252-261. Cambridge: Cambridge University Press.

Fischer, G. (1993). Creativity enhancing design environments. In Modeling creativity and knowledge-based creative design, (Gero, J.S., Maher, M.-L., Ed.), pp. 269-282. Hillsdale, NJ: Lawrence Erlbaum.

Galitz, W.O. (2007). The essential guide to user interface design: an introduction to GUI design principles and techniques. NY: John Wiley \& Sons.

Gaver, W.W., Beaver, J., \& Benford, S. (2003). Ambiguity as a resource for design. Proc. SIGCHI Conf. on Human Factors in Computing Systems, CHI'03, pp. 233-240. Ft. Lauderdale, FL: ACM. 
Gentner, D. (1989). The mechanisms of analogical learning. In Similarity and analogical reasoning, (Vosniadou, S., \& Ortony, A., Eds.), pp. 199-241. Cambridge, UK: Cambridge University Press.

Goel, A.K., McAdams, D.A., \& Stone, R.B. (2014a). Biologically Inspired Design: Computational Methods and Tools. London, UK: Springer-Verlag.

Goel, A.K., Vattam, S., Wiltgen, B., \& Helms, M. (2012). Cognitive, collaborative, conceptual and creative-Four characteristics of the next generation of knowledge-based CAD systems: A study in biologically inspired design. Computer-Aided Design, 44(10), 879900.

Goel, A.K., Vattam, S., Wiltgen, B., \& Helms, M. (2014b). Information-Processing Theories of Biologically Inspired Design. In Biologically Inspired Design, (Goel, A.K., et al., Eds.), pp. 127-152. London: Springer-Verlag.

Goldschmidt, G. (2011). Avoiding design fixation: Transformation and abstraction in mapping from source to target. The Journal of Creative Behavior, 45(2), 92-100.

Greene, S.L. (2002). Characteristics of applications that support creativity. Communications of the ACM, 45(10), 100-104.

Halasz, F., \& Moran, T.P. (1982). Analogy considered harmful. Proc. Conf. on Human Factors in Computing Systems, pp. 383-386. Gaithersburg, MD: ACM.

Hastings, D., \& McManus, H. (2004). A framework for understanding uncertainty and its mitigation and exploitation in complex systems. Proc. Engineering Systems Symposium, pp. 1-19. Cambridge, MA.

Helms, M., \& Goel, A. (2013). Grounded knowledge representations for biologically inspired design. Proc. Int. Conf. on Engineering Design, pp. 351-360. Seoul, Korea: ICED.

Helms, M., Vattam, S.S., \& Goel, A.K. (2009). Biologically inspired design: process and products. Design Studies, 30(5), 606-622. 
Hewett, T. (2005). Informing the design of computer-based environments to support creativity. International Journal of Human-Computer Studies, 63(4), 383-409.

Hewett, T., \& DePaul, J.L. (2000). Toward a human centered scientific problem solving environment. In Enabling Technologies for Computational Science, (Houstis, E.N., et al., Eds.), pp. 79-90. Boston: Kluwer.

Hey, J., Linsey, J., Agogino, A.M., \& Wood, K.L. (2008). Analogies and metaphors in creative design. International Journal of Engineering Education, 24(2), 283-294.

Holland, J.H. (1986). Induction: processes of inference, learning, and discovery. Cambridge, MA: MIT Press.

Holyoak, K.J., Gentner, D., \& Kokinov, B.N. (2001). Introduction: the place of analogy in cognition. In The analogical mind: Perspectives from cognitive science, (Gentner, D., et al., Eds.), pp. 1-19. Cambridge, MA: The MIT Press.

Holyoak, K.J., \& Thagard, P. (1995). Mental leaps: analogy in creative thought. Cambridge, MA: MIT Press.

Howard, T.J., Culley, S.J., \& Dekoninck, E. (2008). Describing the creative design process by the integration of engineering design and cognitive psychology literature. Design Studies, 29(2), 160-180.

Hughes, J.A., O'Brien, J., Rodden, T., Rouncefield, M., \& Viller, S. (2000). Patterns of home life: informing design for domestic environments. Personal and Ubiquitous Computing, 4(1), $25-38$

ISO. (n.d.). ISO 9241 Series: Ergonomic Requirements for Office Work with Visual Display Terminals (VDTs). Geneva, Switzerland: ISO.

Jansson, D.G., \& Smith, S.M. (1991). Design fixation. Design Studies, 12(1), 3-11.

Johnson, G.J., Bruner II, G.C., \& Kumar, A. (2006). Interactivity and its facets revisited:

Theory and empirical test. Journal of advertising, 35(4), 35-52. 
Johnson, H., \& Carruthers, L. (2006). Supporting creative and reflective processes. International Journal of Human-Computer Studies, 64(10), 998-1030.

Kalogerakis, K., Lüthje, C., \& Herstatt, C. (2010). Developing innovations based on analogies: experience from design and engineering consultants. Journal of Product Innovation Management, 27(3), 418-436.

Knippers, J., \& Speck, T. (2012). Design and construction principles in nature and architecture. Bioinspiration \& Biomimetics, 7(1), 015002.

Kules, B. (2005). Supporting creativity with search tools. In NSF Workshop Report on Creativity Support Tools, (Shneiderman, B., et al., Eds.), pp. 53-64. Washington, DC: NSF. Kules, B., \& Shneiderman, B. (2008). Users can change their web search tactics: Design guidelines for categorized overviews. Information Processing \& Management, 44(2), 463484.

Kuniavsky, M. (2003). Observing the user experience: a practitioner's guide to user research. San Francisco, CA: Morgan Kaufmann.

Lepora, N.F., Verschure, P., \& Prescott, T.J. (2013). The state of the art in biomimetics. Bioinspiration \& Biomimetics, 8(1), 013001.

Linsey, J.S., Markman, A.B., \& Wood, K.L. (2012). Design by analogy: A study of the wordtree method for problem re-representation. Journal of Mechanical Design, 134(4), 041009.

Linsey, J.S., Wood, K.L., \& Markman, A.B. (2008). Modality and representation in analogy. Artificial Intelligence for Engineering Design, Analysis and Manufacturing, 22(02), 85-100. Liu, Y., \& Shrum, L. (2002). What is interactivity and is it always such a good thing? Implications of definition, person, and situation for the influence of interactivity on advertising effectiveness. Journal of advertising, 31(4), 53-64. 
Maher, M.L., Balachandran, M., \& Zhang, D.M. (1995). Case-based reasoning in design. Lawrence Erlbaum.

Mak, T.W., \& Shu, L.H. (2004). Abstraction of biological analogies for design. CIRP AnnalsManufacturing Technology, 53(1), 117-120.

Mak, T.W., \& Shu, L.H. (2008). Using descriptions of biological phenomena for idea generation. Research in Engineering Design, 19(1), 21-28.

Nagel, J.K., Nagel, R.L., Stone, R.B., \& McAdams, D.A. (2010). Function-based, biologically inspired concept generation. Artificial Intelligence for Engineering Design, Analysis and Manufacturing, 24(4), 521-535.

Nielsen, J. (1994). Heuristic evaluation. In Usability inspection methods, (Nielsen, J., \& Mack, R.L., Eds.), pp. 25-62. New York, NY: John Wiley \& Sons, Inc.

Nijstad, B.A., Stroebe, W., \& Lodewijkx, H.F. (2002). Cognitive stimulation and interference in groups: Exposure effects in an idea generation task. Journal of experimental social psychology, 38(6), 535-544.

Nørgaard, M., \& Hornbæk, K. (2009). Exploring the Value of Usability Feedback Formats. International Journal of Human-Computer Interaction, 25(1), 49-74.

Oppenheimer, R. (1956). Analogy in science. American Psychologist, 11(3), 127-135.

Pearce, M., Goel, A.K., Kolodner, J.L., Zimring, C., Sentosa, L., \& Billington, R. (1992).

Case-based design support: A case study in architectural design. IEEE Expert, 7(5), 14-20.

Perttula, M., \& Sipilä, P. (2007). The idea exposure paradigm in design idea generation. Journal of Engineering Design, 18(1), 93-102.

Ramey, J., Robinson, C., Carlevato, D., \& Hansing, R. (1992). Communicating User Needs to Designers: Hypermedia-Supported Requirements Documents. Int. Professional Communication Conf., IPCC'92, 241-247. 
Resnick, M., Myers, B., Nakakoji, K., Shneiderman, B., Pausch, R., Selker, T., \& Eisenberg, M. (2005). Design principles for tools to support creative thinking. In NSF Workshop Report on Creativity Support Tools, (Shneiderman, B., et al., Eds.), pp. 25-36. Washington, DC: NSF.

Sarkar, P., \& Chakrabarti, A. (2008). The effect of representation of triggers on design outcomes. Artificial Intelligence for Engineering Design, Analysis and Manufacturing, 22(2), 101-116.

Schneiderman, B., \& Plaisant, C. (2005). Designing the User Interface: Strategies for Effective Human-Computer Interaction, Fourth Edition. Reading, MA: Pearson Education, Limited.

Shneiderman, B. (1997). Direct manipulation for comprehensible, predictable and controllable user interfaces. Proc. Int. Conf. on Intelligent User Interfaces, pp. 33-39. Orlando, Florida, USA: ACM.

Shneiderman, B. (2000). Creating creativity: user interfaces for supporting innovation. $A C M$ Transactions on Computer-Human Interaction, 7(1), 114-138.

Shu, L. (2010). A natural-language approach to biomimetic design. Artificial Intelligence for Engineering Design, Analysis and Manufacturing, 24(4), 507-519.

Spiro, R.J., Feltovich, P.J., Coulson, R.L., \& Anderson, D.K. (1989). Multiple analogies for complex concepts: antidotes for analogy-induced misconception in advanced knowledge aquisition. In Similarity and analogical reasoning, (Vosniadou, S., \& Ortony, A., Eds.), pp. 498-531. Cambridge, UK: Cambridge University Press.

Stacey, M., \& Eckert, C. (2003). Against ambiguity. Computer Supported Cooperative Work, $12(2), 153-183$.

Terry, M., \& Mynatt, E.D. (2002). Recognizing creative needs in user interface design. Proc. Conf. on Creativity \& Cognition, pp. 38-44. Loughborough: ACM. 
The Biomimicry 3.8 Institute. (2008-2014). AskNature. Retrieved July 14, 2014, from http://www.asknature.org/.

Töre Yargın, G. (2013). Developing a Model for Effective Communication of User Research Findings to the Design Process. Unpublished Ph.D. thesis: Middle East Technical University. Töre Yargın, G., \& Erbuğ, Ç. (2012). Information System for Visualizing User Research to Lead Innovation. Proc. DMI 2012 Int. Research Conf., (Bohemia, E., et al., Eds.), pp. 71-85. Boston, MA: DMI.

Vattam, S.S., \& Goel, A.K. (2011). Foraging for Inspiration: Understanding and Supporting the Online Information Seeking Practices of Biologically Inspired Designers. Proc. ASME 2011 Int. Design Engineering Technical Conf. \& Computers and Information in Engineering Conf., pp. 177-186. Denver, CO: ASME.

Verhaegen, P.-A., D’hondt, J., Vandevenne, D., Dewulf, S., \& Duflou, J.R. (2011).

Identifying candidates for design-by-analogy. Computers in industry, 62(4), 446-459.

Vermaas, P.E., \& Eckert, C. (2013). My functional description is better! Artificial Intelligence for Engineering Design, Analysis and Manufacturing, 27(3), 187-190.

Vincent, J.F., Bogatyreva, O.A., Bogatyrev, N.R., Bowyer, A., \& Pahl, A.-K. (2006).

Biomimetics: its practice and theory. Journal of the Royal Society Interface, 3(9), 471-482.

Vosniadou, S., \& Ortony, A. (1989). Similarity and analogical reasoning: a synthesis. In Similarity and analogical reasoning, (Vosniadou, S., \& Ortony, A., Eds.), pp. 1-17.

Cambridge, UK: Cambridge University Press.

Wilson, J.O., Rosen, D., Nelson, B.A., \& Yen, J. (2010). The effects of biological examples in idea generation. Design Studies, 31(2), 169-186.

Yamamoto, Y., \& Nakakoji, K. (2005). Interaction design of tools for fostering creativity in the early stages of information design. International Journal of Human-Computer Studies, 63(4), 513-535. 
Zahner, D., Nickerson, J.V., Tversky, B., Corter, J.E., \& Ma, J. (2010). A fix for fixation?

Rerepresenting and abstracting as creative processes in the design of information systems.

Artificial Intelligence for Engineering Design, Analysis and Manufacturing, 24(2), 231-244.

\section{Author Biographies}

Dr Gülşen Töre-Yargın is a Visiting Post-doctoral Research Associate at the University of Cambridge, Engineering Design Centre. She received her $\mathrm{PhD}$ from the Middle East Technical University (METU), Department of Industrial Design. She holds BID and MSc degrees. Her research interests focuses on communication of research knowledge to design process. She is particularly interested in design and development of research deliverables and information visualization. She also worked as a user researcher. She has gained more than six years of research experience at METU/BILTIR-UTEST Product Usability Unit ranging from user research on consumer products to automotive design.

Dr Nathan Crilly is a Senior Lecturer in Engineering Design at the University of Cambridge. He has a PhD in Design Research and a Bachelors degree in Mechanical Engineering. His research interests are in the areas of design, technology and communication. He employs an interdisciplinary approach to studying how artefacts (e.g. products, systems or services) are developed, the properties they exhibit and the ways in which people use them. Nathan is a Fellow in Engineering at Clare College, Cambridge. He is a member of the Design Research Society and The Design Society. He also serves on the International Editorial Board of Design Studies. 